\title{
COVID-19 in young and middle-aged adults: predictors of poor outcome and clinical differences
}

\author{
Eva Tabernero ${ }^{1,2}$ (D) Luis A. Ruiz ${ }^{1,3} \cdot$ Pedro P. España $^{4} \cdot$ Raúl Méndez $^{5,6} \cdot$ Leyre Serrano $^{1,3} \cdot$ Borja Santos $^{7}$. \\ Ane Uranga ${ }^{4} \cdot$ Paula González ${ }^{5,6} \cdot$ Patricia Garcia $^{4} \cdot$ Antoni Torres $^{8} \cdot$ Rosario Menendez $^{5,6} \cdot$ Rafael Zalacain $^{1}$
}

Received: 19 June 2021 / Accepted: 10 August 2021 / Published online: 31 August 2021

○) Springer-Verlag GmbH Germany, part of Springer Nature 2021

\begin{abstract}
Introduction Young and middle-aged adults are the largest group of patients infected with SARS-CoV-2 and some of them develop severe disease.

Objective To investigate clinical manifestations in adults aged 18-65 years hospitalized for COVID-19 and identify predictors of poor outcome. Secondary objectives: to explore differences compared to the disease in elderly patients and the suitability of the commonly used community-acquired pneumonia prognostic scales in younger populations.

Methods Multicenter prospective registry of consecutive patients hospitalized for COVID-19 pneumonia aged 18-65 years between March and May 2020. We considered a composite outcome of "poor outcome" including intensive care unit admission and/or use of noninvasive ventilation, continuous positive airway pressure or high flow nasal cannula oxygen and/or death.

Results We identified 513 patients $<65$ years of age, from a cohort of 993 patients. 102 had poor outcomes (19.8\%) and 3.9\% died. 78\% and 55\% of patients with poor outcomes were classified as low risk based on CURB and PSI scores, respectively. A multivariate Cox regression model identified six independent factors associated with poor outcome: heart disease, absence of chest pain or anosmia, low oxygen saturation, high LDH and lymphocyte count $<800 / \mathrm{mL}$.

Conclusions COVID-19 in younger patients carries significant morbidity and differs in some respects from this disease in the elderly. Baseline heart disease is a relevant risk factor, while anosmia and pleuritic pain are associated to better prognosis. Hypoxemia, LDH and lymphocyte count are predictors of poor outcome. We consider that CURB and PSI scores are not suitable criteria for deciding admission in this population.
\end{abstract}

Keywords COVID-19 $\cdot$ SARS-CoV-2 $\cdot$ Young adults $\cdot$ Mortality

\section{Introduction}

Severe acute respiratory syndrome coronavirus 2 (SARS$\mathrm{CoV}-2$ ) is currently causing an unprecedented pandemic of severe respiratory illness, coronavirus disease 2019 (COVID-19), more than 140 million cases having been confirmed around the world by April 2021. It represents a challenge for health systems with extraordinarily high numbers of patients hospitalized with COVID-19 viral pneumonia and more than 3 million deaths [1].

The influence of age on the risk of developing severe pneumonia is stronger with SARS-CoV-2 than with other

Eva Tabernero

evataberna@yahoo.es

Extended author information available on the last page of the article pathogens, and a large amount of information has been generated on the characteristics of COVID-19 in elderly and very elderly patients [2-4]. In contrast, much less attention has been paid to one of the most worrying aspects of the pandemic, namely, the severity of the disease in some young and middle-aged patients, this being associated with substantial mortality rates and the need for prolonged invasive mechanical ventilation with the resulting sequelae [5].

Moreover, the number of cases of COVID-19 is increasing rapidly among young adults worldwide. The wider use of diagnostic tests has identified that this population group -individuals between 18 and 65 -years-old-accounts for $75 \%$ of those infected globally, attributable to the fact that they are of working age with high mobility and numerous interpersonal interactions [1]. 
A recent cross-sectional survey in various European and American countries showed that under-65-year-olds account for 4-22\% of all COVID-19 deaths [6]. Another study described a case-fatality rate ranging from 0.2 to 1.3 in Italy and China in individuals aged 20-60 years at the start of the pandemic [7]. The estimated SARS-CoV-2 infectionfatality rate in the general population during the first wave of the COVID-19 pandemic in Spain in 2020 was between 0.01 and $0.38 \%$ in younger age groups (20-60 years)[8].

With the hypothesis that the presentation of COVID-19 pneumonia may be different in young people, we undertook a detailed study of the clinical features, biomarkers and outcomes in the population aged 18-65 years hospitalized for SARS-CoV-2 pneumonia. The main aim was to identify factors predicting risk of clinical deterioration, to escalate the care of at-risk patients. As secondary objectives, we sought to assess potential differences in the characteristics of the disease compared to those in elderly patients, and assess the suitability of the commonly used community-acquired pneumonia (CAP) prognostic scales in this population to facilitate adequate patient care.

For the purpose of this study, we considered a composite outcome of "poor outcome" that included admission to an intensive care unit (ICU) and/or use of noninvasive mechanical ventilation (NIV), continuous positive airway pressure (CPAP), or high flow nasal cannula oxygen (HFNC) therapy and/or death. Similar endpoints have been widely used in other studies [9].

\section{Methods}

\section{Study design and population}

This was a multicenter observational study based on the analysis of a prospective registry of consecutive patients hospitalized for COVID-19 pneumonia between March 1st and May 31st 2020 in three tertiary medical centers (Cruces University Hospital, La Fe University Hospital and Galdakao-Usansolo University Hospital) in Spain. The study was approved by the local ethics committees in accordance with the Declaration of Helsinki's guidelines for research in humans.

We included consecutive patients aged $\geq 18$ years with a new pulmonary infiltrate diagnosed by chest X-ray or computed tomography scan. COVID-19 pneumonia was confirmed by positive reverse transcriptase polymerase chain reaction assay for SARS-CoV-2 in nasopharyngeal swabs.

Patients were excluded if no new pulmonary infiltrates were observed in radiology examinations or if they had previously been hospitalized for COVID-19, as well as if they declined to participate in the study. Pregnant women admitted for delivery were also excluded. We focused on patients aged 18-65-years-old and considered patients $\geq 65$ years hospitalized for SARS-CoV-2 pneumonia as the control group for the initial descriptive study.

\section{Data collection}

We recorded data on demographic characteristics, medication and baseline comorbidities and Charlson's Comorbidity Index. Heart disease included ischemic or congenital heart disease, congestive heart failure and arrhythmia, while lung disease included asthma, chronic obstructive pulmonary disease and interstitial lung disease. Active cancer was defined as malignancy with treatment ongoing or within the previous 6 months. Patients were considered active smokers when they smoked at least 10 cigarettes per day and heavy alcohol users if they reported a daily alcohol intake of at least $80 \mathrm{~g}$ for men or $60 \mathrm{~g}$ for women during the previous year. Obesity was defined as a body mass index $\geq 30 \mathrm{~kg} / \mathrm{m}^{2}$. We classified patients as immunocompromised if they were transplant recipients, had hematological malignancies or used systemic steroids, specifically, $\geq 10 \mathrm{mg} /$ day of prednisone for $>3$ months or other immunosuppressive treatments.

We also collected data on symptoms, vital signs, laboratory and radiological findings on admission to the emergency department and in-hospital course until discharge or death. To assess the severity of pneumonia on admission, we used the Confusion, Urea nitrogen, Respiratory rate, Blood pressure, age $\geq 65$ years (CURB-65) [10] and Pneumonia Severity Index (PSI) scores [11]. Measures of in-hospital clinical course and outcome included: (1) ICU admission; (2) use of invasive mechanical ventilation; (3) use of noninvasive respiratory support or HFNC therapy; (4) in-hospital mortality; and (5) length of hospital stay.

Patients were treated empirically in accordance with current Spanish practice guidelines, based on the Spanish Ministry of Health and the Spanish Agency for Medicine and Health products (AEMPS) in March-April 2020 [12, 13]. In-hospital care was determined by patients' healthcare providers. No interventions were instigated as part of this study.

\section{Study outcome}

The primary objective was to compare the baseline comorbidities, and clinical and laboratory data on admission of young and middle-aged patients with and without poor outcome in terms of respiratory function. This composite poor outcome [9] included admission to an ICU and/or use of NIV, CPAP started as an acute treatment in patients without prior home ventilatory support, or HFNC and/or death) with those without complications. 


\section{Statistical analysis}

Patients hospitalized with COVID-19-related CAP aged $\leq 65$ years were considered the study group. Subgroups for comparisons were also formed by dividing this population using the age thresholds of $18-30,31-50$, and 51-64 years.

Continuous variables are reported as the mean (standard deviation) for normally distributed data and otherwise as the median (interquartile range). Categorical variables are presented as frequency (percentage). For the identification of predictors of mortality, a bivariate analysis was performed. Baseline sociodemographic and clinical factors were compared between the two groups using Student's $t$ test, in the case of continuous variables that followed a normal distribution or the nonparametric Mann-Whitney $U$ test otherwise. The Chi-square test or Fisher's exact test were used for the categorical data. Multivariate analysis was performed using multivariate logistic regression model, including variables with $p$-values lower than 0.100 in the bivariate analysis as predictors. These variables were included in a multivariate logistic regression model in which we eliminated the variables with the highest $p$-values one-by-one until all the variables entered were significant ( $p$-value $<0.05$ ). The Hosmer-Lemeshow goodness-of-fit test for logistic regression was used to assess the fit of the model. The predictive ability of the final multivariate model was assessed by area under the receiver operating characteristic (ROC) curve analysis. Differences were considered statistically significant when $p<0.05$. All analyses were performed using R statistical software (version 4.0.1 R: A language and environment for statistical computing. R Foundation for Statistical Computing, Vienna, Austria).

\section{Results}

We identified 513 patients $<65$ years, from a cohort of 993 patients hospitalized for SARS-COV2 pneumonia (52\% of the total cohort). A considerable number of patients, 102 $(19.8 \%)$ had a poor outcome, with a mortality rate of $3.9 \%$.

\section{Younger patients vs $\geq 65$-year-olds}

The main results are summarized in Table 1. All comorbidities were more frequent in the $\geq 65$-year-olds except for obesity and smoking. There were no differences between the groups in the percentage of immunocompromised patients. Regarding clinical presentation, the younger patients were more likely to show greater severity, being more likely to have fever, myalgia, digestive symptoms, cough, chest pain and anosmia, though confusion was much less common than in the elderly.
Notably, there were no differences in the radiological presentation at the time of admission. On the other hand, all the laboratory inflammatory markers were lower in the $<65$-year-olds (lactate dehydrogenase [LDH], C-reactive protein [CRP], ferritin, and D-dimer) and the lymphocyte and platelet counts were higher in this younger population.

Table 2 summarizes the differences among the age groups regarding the outcomes. There were no differences in rates of ICU admission (14.8 vs $16.6 \%$ ) or use of invasive ventilation (11 vs $12 \%)$, but mortality was notably higher in the elderly $(23.5 \%$ versus $3.9 \%$; $p<0.001)$.

\section{Comparison between different age groups within patients under 65 years}

We formed groups for comparison by dividing the population into the following age groups: $18-30,31-50$ and 51-64 years, containing 17 patients (3.3\%), 170 patients (33.1\%), and 326 patients $(63.5 \%)$, respectively. The corresponding rates of poor outcome were: $0 \%, 13.9 \%$, and $23.3 \%$ respectively, the differences being significant; $p<0.001$. Given that only 17 patients were $\leq 30$-years-old, we decided to merge patients between 18 and 50 years into one group for analysis. Results are summarised in Tables 1 and 2. Once again, older patients were found to have more comorbidities except for obesity (although the difference did not reach significance) and higher levels of inflammatory markers. Patients $\leq 50$-years-old were less likely to be admitted to ICU (11 vs $19 \%)$ and had significantly lower mortality (0.5 vs $5 \%$ ).

\section{Predictors of "poor outcome" in patients under 65 years}

Overall, 102 patients (19.8\%) had a poor outcome. The univariate analysis (Table 3 ) revealed that baseline comorbidities such as heart disease, hypothyroidism and cancer were associated with poor outcome. Baseline treatments were similar in both groups, except for statins. Among the patients with poor outcome, after excluding dyslipidemia, 39\% had no comorbidities, 23 of them went to ICU (4\% of total young patients) and 5 of them died. There were significant differences in clinical presentation, with more confusion and dyspnea and less anosmia and chest pain in the group with poor outcome.

Regarding the physical examination findings, patients with a poor outcome were more likely to have lower diastolic blood pressure, higher respiratory and heart rates and lower blood oxygen levels. Focusing on laboratory findings, poor outcome was significantly associated with high levels of CRP, ferritin, D dimer and LDH, as well as low lymphocyte and platelet counts. 
Table 1 Comparison of baseline characteristics on admission by age

\begin{tabular}{|c|c|c|c|c|c|c|}
\hline & $\geq 65$-year-olds $N=480$ & $<65$-year-olds $N=513$ & $p$ value & {$[18-50] N=187$} & {$[51-64] N=326$} & $p$ value \\
\hline Gender (male) & $298(62.1 \%)$ & $307(59.8 \%)$ & 0.511 & $109(58.3 \%)$ & $198(60.7 \%)$ & 0.652 \\
\hline Heavy alcohol users & $22(7 \%)$ & $16(4.2 \%)$ & 0.27 & $5(3.4 \%)$ & $11(4.8 \%)$ & 0.42 \\
\hline Active smoking & $13(2.8 \%)$ & $35(6.9 \%)$ & 0.005 & $14(7.7 \%)$ & $21(6.6 \%)$ & 0.77 \\
\hline Obesity $(n=726)$ & $130(34.4 \%)$ & $148(42.5 \%)$ & 0.029 & $61(49.2 \%)$ & $87(38.8 \%)$ & 0.079 \\
\hline Hypertension & $318(66.2 \%)$ & $142(27.7 \%)$ & $<0.001$ & $30(16.0 \%)$ & $112(34.4 \%)$ & $<0.001$ \\
\hline Diabetes & $150(31.2 \%)$ & $56(10.9 \%)$ & $<0.001$ & $14(7.5 \%)$ & $42(12.9 \%)$ & 0.08 \\
\hline Heart disease & $140(29 \%)$ & $26(5 \%)$ & $<0.001$ & $1(0.5 \%)$ & $25(7.6 \%)$ & $<0.001$ \\
\hline Lung disease & $211(21.2 \%)$ & $84(16 \%)$ & $<0.001$ & $30(16.0 \%)$ & $54(16.6 \%)$ & 0.976 \\
\hline Cancer & $49(7.4 \%)$ & $8(2.1 \%)$ & $<0.001$ & $11(0.7 \%)$ & $7(3.1 \%)$ & 0.15 \\
\hline Immunosuppression & $20(3.8 \%)$ & $30(5.1 \%)$ & 0.41 & $9(4.2 \%)$ & $21(6.4 \%)$ & 0.37 \\
\hline Comorbidities $\geq 1$ & $451(94 \%)$ & $387(75.4 \%)$ & $<0.001$ & $120(64.2 \%)$ & $267(81.9 \%)$ & 0.001 \\
\hline $\begin{array}{l}\text { Charlson's Comorbid- } \\
\text { ity Index, Median } \\
\text { (IQR) }\end{array}$ & $1.0([0.0-3.0]$ & $0.0[0-1]$ & $<0.001$ & $0.0[0-1]$ & $0.0[0-1]$ & 0.219 \\
\hline $\begin{array}{l}\text { Duration of symptoms, } \\
\text { days before admission } \\
\text { (Median; IQR) }\end{array}$ & $7[5-9]$ & $7[5-10]$ & 0.7 & $7[5-9]$ & $7[6-10]$ & 0.2 \\
\hline Fever & $258(53.8 \%)$ & $338(65.9 \%)$ & $<0.001$ & $136(72.7 \%)$ & $202(62.0 \%)$ & $<0.017$ \\
\hline Cough & $330(68.9 \%)$ & $401(78.3 \%)$ & $<0.001$ & $150(80.2 \%)$ & $251(77.2 \%)$ & 0.48 \\
\hline Dyspnoea & $230(47.9 \%)$ & $276(53.8 \%)$ & 0.07 & $114(61.0 \%)$ & $162(49.7 \%)$ & 0.18 \\
\hline Myalgia & $89(18.6 \%)$ & $151(29.4 \%)$ & $<0.001$ & $54(28.9 \%)$ & $97(29.8 \%)$ & 0.91 \\
\hline Confusion & $51(10.6 \%)$ & $5(0.9 \%)$ & $<0.001$ & $0(0.0 \%)$ & $5(1.5 \%)$ & 0.16 \\
\hline Chest pain & $35(7.3 \%)$ & $67(13.1 \%)$ & 0.004 & $33(17.6 \%)$ & $34(10.4 \%)$ & 0.028 \\
\hline Anosmia & $56(11.7 \%)$ & $140(27.3 \%)$ & $<0.001$ & $59(31.6 \%)$ & $81(24.8 \%)$ & 0.124 \\
\hline Digestive symptoms & $116(24.6 \%)$ & $165(32.6 \%)$ & 0.007 & $65(35.1 \%)$ & $100(31.2 \%)$ & 0.41 \\
\hline $\begin{array}{l}\text { Systolic BP, mmHg } \\
\text { (Median; IQR) }\end{array}$ & 130 [115-147] & 126 [117-138] & 0.014 & 124 [115-134] & 128 [118-141] & 0.016 \\
\hline $\begin{array}{l}\text { Respiratory rate /min } \\
\text { (Median; IQR) }\end{array}$ & 18 [16-24] & 18 [16-22] & 0.068 & $18[16-21]$ & 18 [16-22] & 0.393 \\
\hline $\begin{array}{l}\text { Heart rate/min (Mean; } \\
\text { SD) }\end{array}$ & $88[16.2]$ & $96.9[17.3]$ & $<0.001$ & $99.7(17.6)$ & $95.3(16.9)$ & 0.007 \\
\hline $\begin{array}{l}\mathrm{SaO} 2 \% \text { in room air } \\
\text { (Median; IQR) }\end{array}$ & 94 [90-96] & 96 [93-97] & $<0.001$ & 96 [94-97] & 95 [93-97] & 0.008 \\
\hline $\begin{array}{l}\text { Glucose, mg/dL } \\
\text { (Median; IQR) }\end{array}$ & 119 [106-147] & 106 [97-121] & $<0.001$ & 102 [94-114] & 109 [99-124] & $<0.001$ \\
\hline $\begin{array}{l}\text { Urea, mg/dl (Median; } \\
\text { IQR) }\end{array}$ & $41[32-59]$ & 28 [22-36.5] & $<0.001$ & 25 [19-32] & 30 [24-38] & $<0.001$ \\
\hline $\begin{array}{l}\text { LDH, U/L (Median; } \\
\text { IQR) }\end{array}$ & $326[250-414]$ & $281[232-364]$ & $<0.001$ & 264 [219-328] & 297 [240-382] & $<0.001$ \\
\hline $\begin{array}{l}\text { CRP, mg/L (Median; } \\
\text { IQR) }\end{array}$ & 87 [42-149] & $57.5[26.4-110]$ & $<0.001$ & $43.8[20-89.2]$ & 61.7 [31.2-119] & $<0.001$ \\
\hline $\begin{array}{l}\text { Ferritin, ng/mL } \\
\text { (Median; IQR) }\end{array}$ & 776 [308-1317] & 589 [292-1086] & 0.147 & 475 [139-823] & 671 [367-1187] & 0.002 \\
\hline $\begin{array}{l}\text { Lymphocyte count/ } \mu \mathrm{L} \\
\text { (Median; IQR) }\end{array}$ & $880[620-1200]$ & 1060 [770-1360] & $<0.001$ & 1140 [835-1505] & 990 [735-1288] & $<0.001$ \\
\hline $\begin{array}{l}\text { Platelet count } / \mu \mathrm{L} \\
\text { (Median; IQR) }\end{array}$ & $\begin{array}{l}179,000[140250- \\
242000]\end{array}$ & $\begin{array}{l}198,000[154750- \\
247250]\end{array}$ & 0.001 & $\begin{array}{l}197,000[159500- \\
252000]\end{array}$ & $\begin{array}{l}200,000[154,000- \\
240,000]\end{array}$ & 0.613 \\
\hline $\begin{array}{r}\text { D-Dimer, ng/mL } \\
\text { (Median; IQR) }\end{array}$ & 945 [591-1720] & 570 [354-952] & $<0.001$ & 480 [288-785] & 633 [419-1050] & $<0.001$ \\
\hline CURB score & & & $<0.001$ & & & 0.535 \\
\hline $0-1$ & $190(4.0 \%)$ & $481(74.2 \%)$ & & $179(95.7 \%)$ & $302(93.2)$ & \\
\hline 2 & $204(43 \%)$ & $29(5.6 \%)$ & & $8(4.2 \%)$ & $21(6.4 \%)$ & \\
\hline $3-4$ & $80(16.9 \%)$ & $1(0.2 \%)$ & & $0(0.0 \%)$ & $1(0.3 \%)$ & \\
\hline
\end{tabular}


Table 1 (continued)

\begin{tabular}{|c|c|c|c|c|c|c|}
\hline & $\geq 65$-year-olds $N=480$ & $<65$-year-olds $N=513$ & $p$ value & {$[18-50] N=187$} & {$[51-64] N=326$} & $p$ value \\
\hline PSI score & & & $<0.001$ & & & $<0.001$ \\
\hline $1-2$ & $99(20.8 \%)$ & $421(82.4 \%)$ & & $174(8 \%)$ & $247(76.2 \%)$ & \\
\hline 3 & $168(35.3 \%)$ & $52(10.2 \%)$ & & $11(5.8 \%)$ & $41(12.7 \%)$ & \\
\hline $4-5$ & $209(43.9 \%)$ & $38(7.4 \%)$ & & $2(1.1 \%)$ & $36(11.1 \%)$ & \\
\hline
\end{tabular}

$B P$ blood pressure, $A L T$ alanine aminotransferase, $L D H$ lactate dehydrogenase, $C R P C$-reactive protein

Table 2 In-hospital evolution and outcomes

\begin{tabular}{|c|c|c|c|c|c|c|}
\hline & $\geq 65$-year-olds $N=480$ & $<65$-year-olds $N=513$ & $p$ value & {$[18-50) N=187$} & {$[51-64] N=326$} & $p$ value \\
\hline Length of stay, days (Median-IQR) & $10[6.00-19.0]$ & $9[5-14]$ & 0.003 & $8[5-11.5]$ & 9 [5-15] & 0.023 \\
\hline HFNC & $57(11.9 \%)$ & $54(10.5 \%)$ & 0.566 & $13(6.9 \%)$ & $41(12.6 \%)$ & 0.65 \\
\hline CPAP & $22(4.5 \%)$ & $7(1.3 \%)$ & 0.01 & $2(1.0 \%)$ & $5(1.5 \%)$ & 1 \\
\hline Non-invasive ventilation & $4(0.8 \%)$ & $4(0.7 \%)$ & 0.1 & $1(0.5 \%)$ & $3(0.9 \%)$ & 0.8 \\
\hline Mechanical ventilation & $56(11.7 \%)$ & $65(12.7 \%)$ & 0.699 & $17(9.1 \%)$ & $48(14.7 \%)$ & 0.88 \\
\hline ICU admission & $71(14.8 \%)$ & $85(16.6 \%)$ & 0.495 & $21(11.2 \%)$ & $64(19.6 \%)$ & 0.01 \\
\hline Death & $113(23.5 \%)$ & $20(3.9 \%)$ & $<0.001$ & $1(0.5 \%)$ & $19(5.8 \%)$ & 0.006 \\
\hline
\end{tabular}

$H F N C$ high flow nasal cannula oxygen, $C P A P$ continuous positive airway pressure, $I C U$ intensive care unit

The median duration of symptoms before admission was 7 days with no significant differences between groups in the multivariate analysis.

Patients with severe respiratory disease did have worse CURB and PSI scores, but $78 \%$ of patients with a poor outcome were classified as low risk based on CURB score (0-1) and $55 \%$ based on PSI score (1-2).

In the multivariate analysis, six independent factors were found to be associated with clinical deterioration (Table 3): heart disease (OR: 5.41; 95\% CI 1.72-16.60; $p=0.003$ ), chest pain (OR: $0.19 ; 95 \%$ CI $0.03-0.74 ; p=0.033$ ), anosmia (OR: $0.34 ; 95 \%$ CI $0.13-0.76 ; p=0.014)$, median oxygen saturation (OR: $0.72 ; 95 \%$ CI $0.65-0.80 ; p<0.001), \mathrm{LDH}$ (OR: 1.04; 95\% CI 1.01-1.07; $p=0.006$ ) and lymphocyte count $>800 / \mathrm{mL}$ (OR: 0.46; 95\% CI 0.24-0.87; $p=0.017$ ). The Hosmer-Lemeshow goodness-of-fit test for logistic regression gave a $p$ value of 0.6554 . In the ROC curve analysis, the area under the curve was 0.88 . Figure 1.

\section{Discussion}

This multicenter study provides a comprehensive evaluation of host-related factors, process of care and outcome in a consecutive series of young adults hospitalized with SARS-CoV-2 pneumonia. To our knowledge, this is among the largest series published on this topic to date. Our results show that $19.8 \%$ of the young patients had a poor outcome, with severe respiratory failure, and $3.9 \%$ died. Taken together 18- to 65-year-olds accounted for $52 \%$ of all COVID-19 patients admitted to hospital. Our data reveal that a notable proportion of nonelderly patients develop severe disease and confirm that the burden of young and middle-aged adults with COVID19 hospitalized with severe disease is significant. These findings are consistent with the rates Cunningham et al. found using a national all-payer hospital database in adults aged 18-34 years admitted to US hospitals, namely, 21\% required intensive care and $2.7 \%$ died [14]. Notably, Altonen et al. reported an even higher mortality rate of $13 \%$ in this population in New York City public hospitals [15]. Recent data from the from the Spanish Ministry of Health show that more than 2 million patients between 20 and 60 years of age have been infected with SARS-CoV-2 and $3.9 \%$ of them have required hospitalization; $0.39 \%$ ( $10 \%$ of hospitalized patients) have been admitted to the ICU with an overall mortality rate of $0.1 \%$ [16].

The results of our study illustrate that there are some differences between adults hospitalized for SARS-CoV-2 pneumonia by age. All comorbidities are more frequent in the elderly except obesity and smoking. Obesity is a wellrecognized risk factor for severe COVID-19 and death in young patients, probably due to the proinflammatory status associated with abdominal visceral adiposity and a high expression of angiotensin converting enzyme 2 (ACE2) receptors in adipose tissue [17-21]. It should be noted that $60 \%$ of the nonelderly patients had at least one comorbidity (and the rate was somewhat higher [70.6\%] in those with poor outcomes), some risk factors overlapping with those observed in elderly patients. 
Table 3 Predictors of "poor outcome" in patients under 65 years

\begin{tabular}{|c|c|c|c|c|c|c|}
\hline & \multirow[t]{2}{*}{ All $N=513$} & \multirow{2}{*}{$\begin{array}{l}\text { Favorable outcome } \\
N=411\end{array}$} & \multirow[t]{2}{*}{ Poor outcome $N=102$} & & \multicolumn{2}{|c|}{ Multivariate analysis } \\
\hline & & & & & OR $(95 \% \mathrm{CI})$ & $p$ value \\
\hline Gender (male) & $307(59.8 \%)$ & $230(56.0 \%)$ & $77(75.5 \%)$ & & & \\
\hline Age, years & & & & 0.008 & & \\
\hline $18-30$ & $17(3.3 \%)$ & $17(4.1 \%)$ & $0(0.0 \%)$ & & & \\
\hline $31-50$ & $170(33.1 \%)$ & $144(35.0 \%)$ & $26(25.5 \%)$ & & & \\
\hline $50-65$ & $326(63.5 \%)$ & $250(60.8 \%)$ & $76(74.5 \%)$ & & & \\
\hline Smoking & $35(6.9 \%)$ & $29(7.2 \%)$ & $6(6.12 \%)$ & 0.878 & & \\
\hline $\begin{array}{l}\text { Comorbidities } \geq 1 \\
\text { (excluding dyslipi- } \\
\text { demia) }\end{array}$ & $309(60.2 \%)$ & $237(57.5 \%)$ & $72(70.6 \%)$ & 0.023 & & \\
\hline $\begin{array}{l}\text { Charlson's Comorbidity } \\
\text { Index (Median-IQR) }\end{array}$ & $0.0(0.00-1.00)$ & $0.0(0.00-1.00)$ & $0.0(0.00-1.00)$ & 0.291 & & \\
\hline Obesity $(N=348)$ & $148(42.5 \%)$ & $117(42.2 \%)$ & $31(43.7 \%)$ & 0.935 & & \\
\hline Hypertension & $142(27.7 \%)$ & $107(26.0 \%)$ & $35(34.3 \%)$ & 0.121 & & \\
\hline Diabetes & $56(10.9 \%)$ & $44(10.7 \%)$ & $12(11.8 \%)$ & 0.897 & & \\
\hline Dyslipidemia & $142(27.7 \%)$ & $107(26.0 \%)$ & $35(34.3 \%)$ & 0.121 & & \\
\hline Heart disease & $26(5.0 \%)$ & $13(3.1 \%)$ & $13(12.7 \%)$ & $<0.001$ & $5.41(01.72,16.6)$ & 0.003 \\
\hline $\begin{array}{l}\text { Chronic kidney disease } \\
(N=373)\end{array}$ & $15(4.0 \%)$ & $10(3.3 \%)$ & $5(6.9 \%)$ & 0.180 & & \\
\hline Lung disease & $84(16.4 \%)$ & $66(16.1 \%)$ & $18(17.6 \%)$ & 0.811 & & \\
\hline $\begin{array}{l}\text { Peripheral vascular } \\
\text { disease }\end{array}$ & $8(1.5 \%)$ & $6(1.4 \%)$ & $2(1.9 \%)$ & 0.662 & & \\
\hline Malignancy & $8(2.1 \%)$ & $4(1.3 \%)$ & $4(5.5 \%)$ & 0.048 & & \\
\hline $\begin{array}{l}\text { Hypothyroidism } \\
(N=321)\end{array}$ & $24(7.4 \%)$ & $24(9.4 \%)$ & $0(0.0 \%)$ & 0.006 & & \\
\hline Immunosuppression & $30(5.1 \%)$ & $22(5.3 \%)$ & $8(7.8 \%)$ & 0.493 & & \\
\hline ACE inhibitors & $107(20.9 \%)$ & $81(19.7 \%)$ & $26(25.5 \%)$ & 0.250 & & \\
\hline Statins & $97(18.9 \%)$ & $70(17.0 \%)$ & $27(26.5 \%)$ & 0.042 & & \\
\hline \multicolumn{7}{|l|}{ Corticoids } \\
\hline None & $456(88.9 \%)$ & $362(88.1 \%)$ & $94(92.2 \%)$ & 0.403 & & \\
\hline Inhaled & $43(8.3 \%)$ & $38(9.2 \%)$ & $5(4.9 \%)$ & & & \\
\hline Oral & $14(2.7 \%)$ & $11(2.6 \%)$ & $3(2.9 \%)$ & & & \\
\hline $\begin{array}{l}\text { Duration of symptoms } \\
\text { (days) before admis- } \\
\text { sion Median (IQR) }\end{array}$ & $7[5-10]$ & $7[6-10]$ & $7[5-8]$ & $<0.001$ & & \\
\hline Fever & $338(65.9 \%)$ & $263(64.0 \%)$ & $75(73.5 \%)$ & 0.089 & & \\
\hline Cough & $401(78.3 \%)$ & $319(77.8 \%)$ & $82(80.4 \%)$ & 0.665 & & \\
\hline Dyspnoea & $276(53.8 \%)$ & $207(50.4 \%)$ & $69(67.6 \%)$ & 0.003 & & \\
\hline Myalgia & $151(29.4 \%)$ & $125(30.4 \%)$ & $26(25.5 \%)$ & 0.392 & & \\
\hline Confusion & $5(0.9 \%)$ & $1(0.2 \%)$ & $4(3.9 \%)$ & 0.006 & & \\
\hline Chest pain & $67(13.1 \%)$ & $60(14.6 \%)$ & $7(6.8 \%)$ & 0.056 & $\begin{array}{l}0.19 \\
(0.03,0.74)\end{array}$ & 0.033 \\
\hline Anosmia & $140(27.3 \%)$ & $140(27.3 \%)$ & $14(13.7 \%)$ & 0.001 & $0.34(0.13,0.76)$ & 0.014 \\
\hline Digestive symptoms & $165(32.6 \%)$ & $138(34.2 \%)$ & $27(26.5 \%)$ & 0.173 & & \\
\hline $\begin{array}{l}\text { Systolic BP, mmHg } \\
\text { (Median-IQR) }\end{array}$ & $126[117-138]$ & 126 [118-138] & 124 [115-135] & 0.301 & & \\
\hline $\begin{array}{l}\text { Respiratory rate /min } \\
\text { (Median-IQR) }\end{array}$ & 18.0 [16-22] & $17.0[16-20]$ & 24.0 [19-32] & $<0.001$ & & \\
\hline $\begin{array}{l}\text { Heart rate/min } \\
\text { (Mean;SD) }\end{array}$ & $96.9(17.3)$ & $96.5(16.9)$ & $98.7(18.7)$ & 0.293 & & \\
\hline
\end{tabular}


Table 3 (continued)

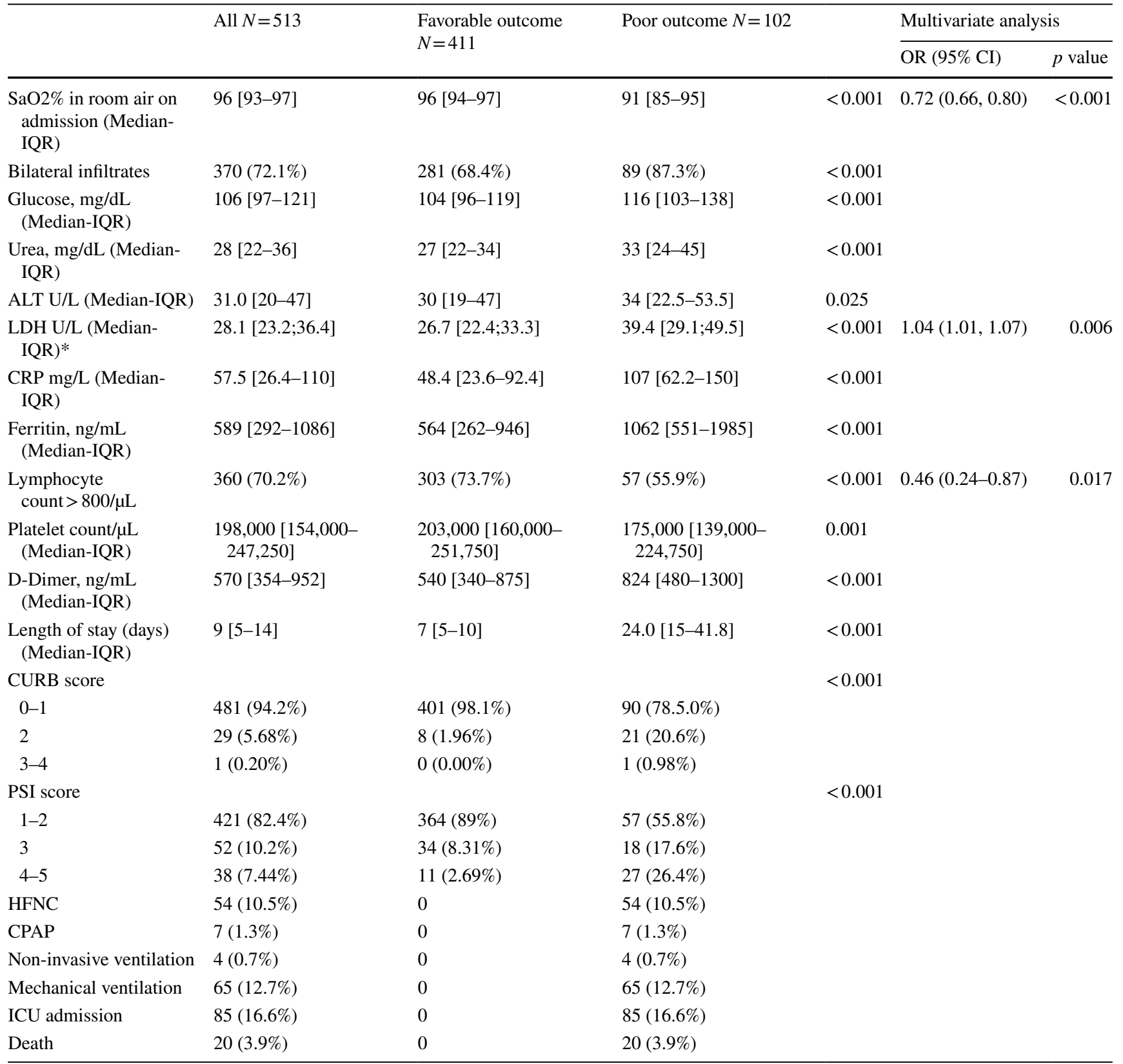

$B P$ blood pressure, $A L T$ alanine aminotransferase, $L D H$ lactate dehydrogenase *LDH is presented for every 10 unit increase, $C R P C$-reactive protein, $O R$ odds ratio, $C I$ confidence interval

Area under the receiver operating characteristic curve $(95 \% \mathrm{CI})=0.88$

Hosmer-Lemeshow $p$ value $=0.655$

There are also several differences in clinical presentation. Patients under 65 years of age are more symptomatic, in particular, more often having fever, chest pain, myalgia and especially anosmia, likely a consequence of a stronger immune response. Conversely, confusion is very rare in younger patients. All laboratory parameters are worse in the elderly population. Some of these findings have been observed previously in retrospective research [22].
Though the rates of intubation, respiratory support or HFNC are similar in the two groups, there are clear differences in the mortality rate (3.9\% vs $23.5 \%$ ). Many elderly patients died without being intubated. On the other hand, young patients who received mechanical ventilation had a better prognosis, probably because of the age effect on functional reserve and ability to recover. 
Fig. 1 Area under the curve (ROC) multivariate logistic regression of factors associated with poor evolution in patients aged $18-65$. Area under the curve: 0.886

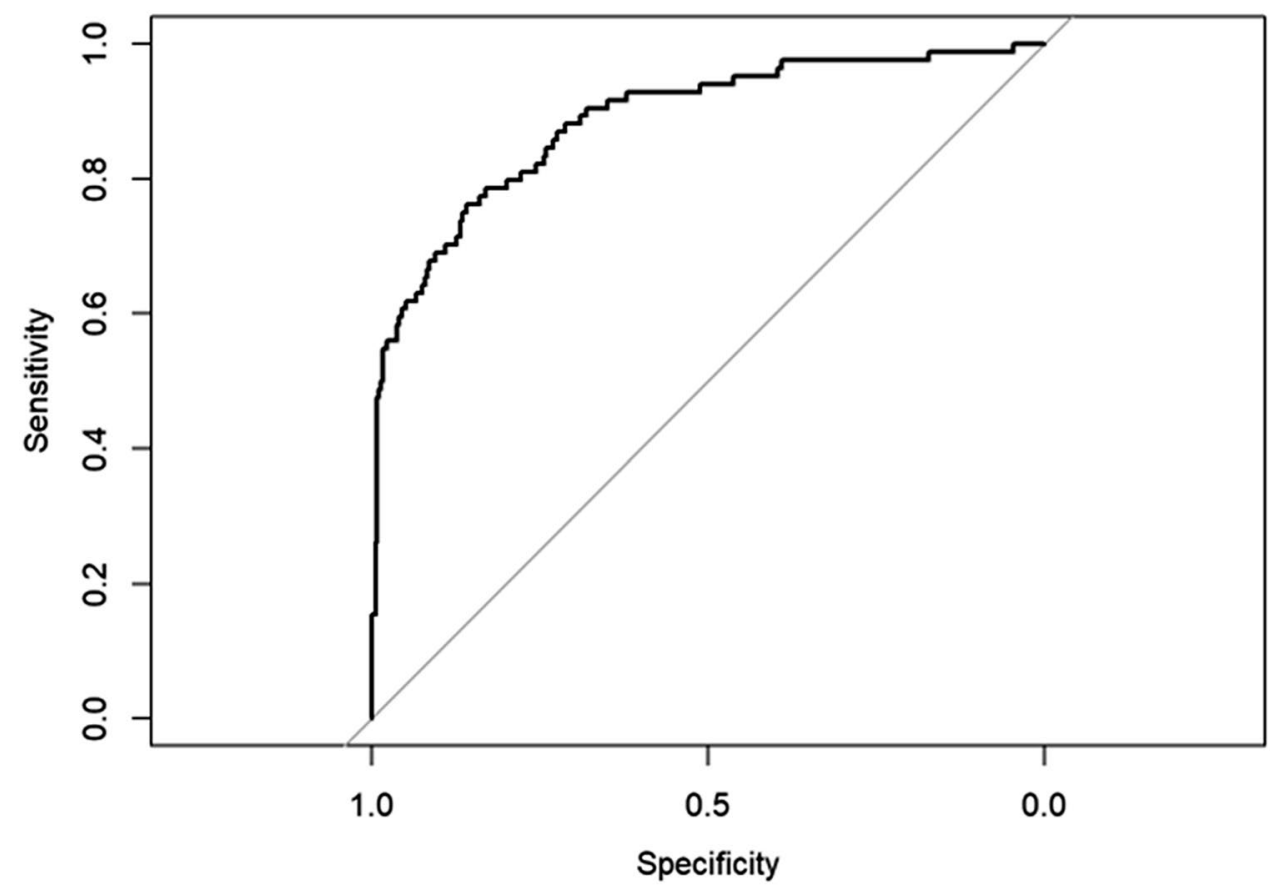

For the purpose of our analysis, we define "poor outcome" as a composite index that included ICU admission and/or use of CPAP, noninvasive ventilation, HFNC or death. Although ICU admission may be subjective, in high pressure conditions as in the first wave in Spain, only those who really needed it were admitted to the ICU, as shown by the fact that $92 \%$ of them needed mechanical ventilation or HFNC.

The multivariate analysis identified six factors associated with poor outcome patients under 65 years of age. All these can be assessed based on data available on admission and could help to determine the initial site and intensity of care. The only baseline comorbidity that carried a significant risk in our study was heart disease. Numerous studies have shown that patients with underlying heart diseases have higher odds of death from COVID-19 [23-26] and it has also been described as a risk factor in a younger population [15]. The worse prognosis of COVID-19 in patients with a history of heart disease could be related to elevated expression of ACE2 and a higher baseline production and release of renin. Heart disease in populations with a low prevalence of that type of comorbidity, such as non-elderly patients, behaves as a major risk factor for poor outcome and should be considered when evaluating young patients with COVID-19 and might also be a justification for prioritizing vaccination or future preventive therapies.

Regarding clinical symptoms affecting younger patients, pleuritic pain is associated with a better outcome. This has been previously reported as an independent prognostic factor in patients with CAP and bacteremia. Although the reason for this remains unclear, it has been suggested that it may be because these patients seek medical attention earlier or that pain reflects a stronger immune response [27-29].

The second clinical feature that was significant in the multivariate analysis is anosmia, one of the most characteristic symptoms of COVID-19, and present in $27 \%$ of our under-65-year-old patients. In some previous studies, it has been associated with a lower odds of severe coronavirus disease and death. This might be related to a different inflammatory profile with a better local immune response, which could limit the spread of the virus in the body resulting in less severe disease but also a stronger local inflammatory response that could affect olfactory cells [30-32].

Oxygen saturation is the finding from the examination at admission that was most significant in the multivariate analysis. In this sense, our study confirms previously published results, a recent systematic evaluation of 22 prognostic models concluding that baseline oxygen saturation in room air is the strongest predictor of deterioration [9]. The measurement of oxygen saturation could provide an opportunity for innovation and telemedicine in this younger population.

We identified lymphocyte count and LDH level as significant laboratory variables in the multivariate analysis. To date, almost 100 different predictive models with sophisticated statistical models and some systematic reviews have been published on COVID prognosis. Our results are generally in line with these studies, LDH level and lymphocyte count being included in most of the models, although they have not been focused on adults under 65-years-old [26, 33-36]. LDH is expressed extensively in body tissues, including the lungs and it is released during tissue damage, indicating the extent of the disease. 
In a recent meta-analysis, $\mathrm{LDH}>250 \mathrm{U} / \mathrm{L}$ was associated with poor prognosis [37]. Early in the pandemic, lymphopenia was recognized as a useful marker of progression and severe coronavirus disease. Lymphocytes express the ACE2 receptor of the virus and could be a target for the virus. Apoptosis or functional exhaustion of cytotoxic lymphocytes as a response to hyperinflammation has also been proposed as an explanation for the depletion of lymphocytes [38].

Finally, one of the main conclusions of our study is the poor performance of the traditional scores for outpatient treatment of CAP, namely, PSI and CURB in this population $\leq 65$-years-old with COVID pneumonia. As many as $78 \%$ of our young and middle-aged patients with poor outcome would have been classified as low risk based on their CURB score (0-1) and $55.8 \%$ based on their PSI score (1-2). There is much controversy regarding this topic with little agreement but clearly CURB and PSI scores underestimate severity in young COVID-19 patients and should not be used. This lack of accuracy could be because these scores do not consider inflammatory response parameters which play an important role in the pathogenesis of COVID-19 with an excessive production of proinflammatory cytokines, the so-called cytokine storm. CURB score does not include hypoxemia either, and severe COVID-19 is characterized by severe respiratory insufficiency [39, 40].

There are several limitations in our study. First, some anthropometric data were missing especially in patients who went directly to the ICU and died, this explaining the nonsignificance of obesity as a risk factor for poor outcome in our patients. Second, data were collected between March and May, during the first wave of COVID and medical treatments, ventilatory support practices and also the COVID stains have changed since then and hence the outcomes might be different now. Third, it is an observational study and treatment strategies were not uniform across hospitals or over time. Unfortunately, a definitive effective treatment has yet to be identified. Fourth, the number of young patients with comorbidities is surprisingly high and this could have affected the results and introduced bias.

To conclude, our results show that COVID-19 is associated with significant morbidity in younger patients and underline the importance of infection prevention measures in this active and working-age group, especially in the presence of comorbidities. COVID-19 in under-65-year-olds differs in some respects from this disease in elderly populations, with heart disease being an important risk factor, anosmia and pleuritic pain more frequent and associated to better prognosis, and hypoxemia, high LDH and low lymphocyte count as predictors of a poor outcome. We consider that low CURB or PSI scores are not suitable criteria for recommending outpatient management in this population.
Author contributions ETH and LAR take the responsibility of the manuscript as a whole. ETH, LAR, RZJ, RMV, RMO and PPE conceived and designed the study. AUE, PGH, PGJ, RMO, and LAR enrolled patients and collected and compiled data. BSZ performed the statistical analysis. ETH, RZJ, LAR, RMO, ATM, PPE, and RMV analyzed and interpreted the data. ETH, RZJ, LSF and LAR wrote the manuscript. RMV, RMO, ATM, AUE and PPE commented and revised the report. All authors read and approved the final manuscript.

Funding This research did not receive any specific grant form funding agencies in the public, commercial, or not-for-profit sectors.

Availability of data and materials The data that support the findings of this study are available on request from the corresponding author.

\section{Declarations}

Conflict of interest The authors declare that they have no conflict of interest.

Ethical approval The Biomedical Research Ethics Committee of Euskadi (PI2020-083) approved this study.

Consent for publication All authors have accepted the publication of the manuscript.

\section{References}

1. European Centre for Diseases Prevention and Control. Weekly COVID-19 country overview. Stockholm ECDC; 2020. Available from: https://www.ecdc.europa.eu/en/covid-19/countryoverviews. Accessed 202030 December.

2. Bonanad C, García-Blas S, Tarazona-Santabalbina F, Sanchis J, Bertomeu-González V, Fácila L, Ariza A, Núñez J, Cordero A. The effect of age on mortality in patients with COVID-19: a meta-analysis with 611,583 subjects. J Am Med Dir Assoc. 2020;21:915-91.

3. Liu K, Chen Y, Lin R, Han K. Clinical features of COVID-19 in elderly patients: a comparison with young and middle-aged patients. J Infect. 2020;80:e14-8. https://doi.org/10.1016/j.jinf. 2020.03.005.

4. Li P, Chen L, Liu Z, Pan J, Zhou D, Wang H, Gong H, Fu Z, Song Q, Min Q, Ruan S, Xu T, Cheng F, Li X. Clinical features and short-term outcomes of elderly patients with COVID- 19 . Int J Infect Dis. 2020;97:245-50. https://doi.org/10.1016/j.ijid. 2020.05.107 (Epub 2020 May 31. PMID: 32492533; PMCID: PMC7261456).

5. Zhang L, Fan T, Yang S, Feng H, Hao B, Lu Z, Xiong R, Shen $\mathrm{X}$, Jiang W, Wang W, Geng Q. Comparison of clinical characteristics of COVID-19 between elderly patients and young patients: a study based on a 28-day follow-up. Aging (Albany NY). 2020;12:19898-910. https://doi.org/10.18632/aging.104077 (Epub 2020 Oct 26. PMID: 33106442; PMCID: PMC7655161)

6. Ioannidis JPA, Axfors C, Contopoulos-Ioannidis DG. Populationlevel COVID-19 mortality risk for non-elderly individuals overall and for non-elderly individuals without underlying diseases in pandemic epicenters. Environ Res. 2020;188:109890. https:// doi.org/10.1016/j.envres.2020.109890 (Epub 2020 Jul 1. PMID: 32846654; PMCID: PMC7327471).

7. Onder G, Rezza G, Brusaferro S. Case-fatality rate and characteristics of patients dying in relation to COVID-19 in Italy. JAMA. 2020;323:1775-6. https://doi.org/10.1001/jama.2020.4683. 
8. Pastor-Barriuso R, Pérez-Gómez B, Hernán MA, Pérez-Olmeda $\mathrm{M}$, Yotti R, Oteo-Iglesias J, et al. Infection fatality risk for SARSCoV-2 in community dwelling population of Spain: nationwide seroepidemiological study. BMJ. 2020;371: m4509. https://doi. org/10.1136/bmj.m4509.

9. Gupta RK, Marks M, Samuels THA, Luintel A, Rampling T, Chowdhury H, Quartagno M, Nair A, Lipman M, Abubakar I, van Smeden M, Wong WK, Williams B, Noursadeghi M. UCLH COVID-19 Reporting Group. Systematic evaluation and external validation of 22 prognostic models among hospitalised adults with COVID-19: an observational cohort study. Eur Respir J. 2020;56:2003498. https://doi.org/10.1183/13993003.03498-2020 (PMID: 32978307; PMCID: PMC7518075).

10. Lim WS, Van der Eerden MM, Laing R, et al. Defining community-acquired pneumonia severity on presentation to hospital: an international derivation and validation study. Thorax. 2003;58:377-82. https://doi.org/10.1136/thorax.58.5.377.

11. Fine MJ, Stone RA, Singer DE, et al. Processes and outcomes of care for patients with community-acquired pneumonia: results from the Pneumonia Patient Outcomes Research Team (PORT) Cohort Study. Arch Intern Med. 1999;159:970-80. https://doi.org/ 10.1001/archinte.159.9.970.

12. Documento técnico. Manejo clínico del COVID-19: tratamiento médico. 19 de marzo de 2020. Ministerio de Sanidad, Gobierno de España. http://www.aeemt.com/web/wpcontent/uploads/2020/ 03/4_6026300193912129107.pdf

13. Tratamientos disponibles para el manejo de la infección respiratoria por SARS-CoV-2.18 de marzo de 2020. Agencia Española de Medicamentos y Productos Sanitarios. Ministerio de Sanidad, Gobierno de España. https://www.aemps.gob.es/laAEMPS/docs/ medicamentos-disponibles-SARS-CoV-2-19-3-2020.pdf.

14. Cunningham JW, Vaduganathan M, Claggett BL, Jering KS, Bhatt AS, Rosenthal N, Solomon SD. Clinical OUTCOMES in Young US Adults Hospitalized With COVID-19. JAMA Intern Med. 2020;9:e205313. https://doi.org/10.1001/jamainternmed. 2020.5313 (Epub ahead of print. PMID: 32902580; PMCID: PMC7489373).

15. Altonen BL, Arreglado TM, Leroux O, Murray-Ramcharan M, Engdahl R. Characteristics, comorbidities and survival analysis of young adults hospitalized with COVID-19 in New York City. PLoS ONE. 2020;15: e0243343. https://doi.org/10.1371/journal. pone.0243343 (PMID:33315929;PMCID:PMC7735602).

16. Situacion de COVID-19 en España a 28 de Julio de 2021. Informe 89. Equipo COVID-19. RENAVE. CNE. CNM. ISCIII. Ministerio de Sanidad, Gobierno de España. https://www.isciii.es/QueHa cemos/Servicios/VigilanciaSaludPublicaRENAVE/Enfermedad esTransmisibles/Paginas/InformesCOVID-19.aspx

17. Lighter J, Phillips M, Hochman S, Sterling S, Johnson D, Francois $\mathrm{F}$, Stachel A. Obesity in patients younger than 60 years is a risk factor for COVID-19 hospital admission. Clin Infect Dis. 2020;71:896-7. https://doi.org/10.1093/cid/ciaa415 (PMID:322 71368;PMCID:PMC7184372).

18. Zhang F, Xiong Y, Wei Y, Hu Y, Wang F, Li G, et al. Obesity predisposes to the risk of higher mortality in young COVID-19 patients. J Med Virol. 2020;92:1-7. https://doi.org/10.1002/jmv. 26039.

19. Deng M, Qi M, Deng L, Wang H, Xu Y, Li Z, et al. Obesity as a potential predictor of disease severity in young COVID-19 patients: a retrospective study. Obesity. 2020;28:1815. https://doi. org/10.1002/oby.22943.

20. Steinberg E, Wright E, Kushner B. In young adults with COVID19 , obesity is associated with adverse outcomes. West J Emerg Med. 2020;21:752-5. https://doi.org/10.5811/westjem.2020.5. 47972.

21. Hussain A, Mahawar K, Xia Z, Yang W, El-Hasani S. Obesity and mortality of COVID-19 Meta-analysis. Obes Res Clin Pract.
2020;14:295-300. https://doi.org/10.1016/j.orcp.2020.07.002 (Epub 2020 Jul 9. PMID: 32660813; PMCID: PMC7346803).

22. Mori H, Obinata H, Murakami W, Tatsuya K, Sasaki H, Miyake $\mathrm{Y}, \mathrm{t}$ al. . Comparison of COVID-19 disease between young and elderly patients: Hidden viral shedding of COVID-19. J Infect Chemother. 2021. https://doi.org/10.1016/j.jiac.2020.09.003.

23. Tan W, Aboulhosn J. The cardiovascular burden of coronavirus disease 2019 (COVID-19) with a focus on congenital heart disease. Int J Cardiol. 2020;309:70-7. https://doi.org/10.1016/j. ijcard.2020.03.063 (Epub 2020 Mar 28. PMID: 32248966; PMCID: PMC7102656).

24. Zhou F, Yu T, Du R, Fan G, Liu Y, Liu Z, Xiang J, Wang Y, Song B, Gu X, Guan L, Wei Y, Li H, Wu X, Xu J, Tu S, Zhang Y, Chen H, Cao B. Clinical course and risk factors for mortality of adult inpatients with COVID-19 in Wuhan, China: a retrospective cohort study. Lancet. 2020;395:1054-62. https://doi.org/10.1016/ S0140-6736(20)30566-3 (Epub 2020 Mar 11).

25. Tian W, Jiang W, Yao J, Nicholson CJ, Li RH, Sigurslid HH, Wooster L, Rotter JI, Guo X, Malhotra R. Predictors of mortality in hospitalized COVID-19 patients: a systematic review and meta-analysis. J Med Virol. 2020;92:1875-83. https://doi.org/10. 1002/jmv.26050 (Epub 2020 Jul 11. PMID: 32441789; PMCID: PMC7280666).

26. España PP, Bilbao A, García-Gutiérrez S, et al. Predictors of mortality of COVID-19 in the general population and nursing homes. Intern Emerg Med. 2021. https://doi.org/10.1007/ s11739-020-02594-8.

27. Torres A, Cillóniz C, Ferrer M, Gabarrús A, Polverino E, Villegas $\mathrm{S}$, et al. Bacteraemia and antibiotic-resistant pathogens in community acquired pneumonia: risk and prognosis. Eur Respir J. 2015;45:1353-63. https://doi.org/10.1183/09031936.00152514.

28. Fine M, MD, MSc, Smith, Melanie, , et al. Prognosis and outcomes of patients with community-acquired pneumonia: a metaanalysis. JAMA. 1996;275:134-41.

29. Ortqvist A, Hedlund J, Grillner L, Jalonen E, Kallings I, Leinonen M, Kalin M. Aetiology, outcome and prognostic factors in community-acquired pneumonia requiring hospitalization. Eur Respir J. 1990;3:1105-13 (PMID: 2090471).

30. Talavera B, García-Azorín D, Martínez-Pías E, Trigo J, Hernández-Pérez I, Valle-Peñacoba G, Simón-Campo P, de Lera M, Chavarría-Miranda A, López-Sanz C, Gutiérrez-Sánchez M, Martínez-Velasco E, Pedraza M, Sierra Á, Gómez-Vicente B, Guerrero Á, Arenillas JF. Anosmia is associated with lower in-hospital mortality in COVID-19. J Neurol Sci. 2020;419:117163. https:// doi.org/10.1016/j.jns.2020.117163 (Epub 2020 Oct 1. PMID: 33035870).

31. Carrillo-Larco RM, Altez-Fernandez C. Anosmia and dysgeusia in COVID-19: a systematic review. Wellcome Open Res. 2020;13(5):94. https://doi.org/10.12688/wellcomeopenres. 15917.1 (PMID:32587902;PMCID:PMC7308993).

32. Lechien JR, Chiesa-Estomba CM, Beckers E, Mustin V, Ducarme $\mathrm{M}$, Journe F, et al. Prevalence and 6-month recovery of olfactory dysfunction: a multicentre study of 1363 COVID-19 patients (Brief Report). J Intern Med. 2021. https://doi.org/10.1111/joim. 13209.

33. Wynants L, Van Calster B, Collins GS, Riley RD, Heinze G, Schuit E, et al. Prediction models for diagnosis and prognosis of covid-19 infection: systematic review and critical appraisal. BMJ. 2020;7: m1328. https://doi.org/10.1136/bmj.m1328.

34. de Terwangne C, Laouni J, Jouffe L, Lechien JR, Bouillon V, Place S, Capulzini L, Machayekhi S, Ceccarelli A, Saussez S, Sorgente A, Epibase Team OBO. Predictive Accuracy of COVID19 World Health Organization (WHO) Severity Classification and Comparison with a Bayesian-Method-Based Severity Score (EPISCORE). Pathogens. 2020;9:880. https://doi.org/10.3390/patho gens9110880. 
35. Grifoni E, Valoriani A, Cei F, Vannucchi V, Moroni F, Pelagatti L, Tarquini R, Landini G, Masotti L. The CALL score for predicting outcomes in patients with COVID-19. Clin Infect Dis. 2021;72:182-3. https://doi.org/10.1093/cid/ciaa686 (PMID:324 74605;PMCID:PMC7314186).

36. Zhu JS, Ge P, Jiang C, et al. Deep-learning artificial intelligence analysis of clinical variables predicts mortality in COVID-19 patients. JACEP Open. 2020;1:1364-73. https://doi.org/10.1002/ emp2.12205.

37. Martha JW, Wibowo A, Pranata R. Prognostic value of elevated lactate dehydrogenase in patients with COVID-19: a systematic review and meta-analysis. Postgrad Med J. 2021. https://doi.org/ 10.1136/postgradmedj-2020-139542 (Epub ahead of print. PMID: 33452143).
38. Huang I, Pranata R. Lymphopenia in severe coronavirus disease-2019 (COVID-19): systematic review and meta-analysis. J Intensive Care. 2020;24:36. https://doi.org/10.1186/s40560-02000453-4 (PMID:32483488;PMCID:PMC7245646).

39. García Clemente MM, Herrero Huertas J, Fernández Fernández A, et al. Assessment of risk scores in COVID-19. Int J Clin Pract. 2020. https://doi.org/10.1111/ijcp.13705.

40. Satici C, Demirkol MA, Altunok ES, Gursoy B, Alkan M, Kamat S, Demirok B, Surmeli CD, Calik M, Cavus Z, et al. Performance of pneumonia severity index and CURB-65 in predicting 30-day mortality in patients with COVID-19. Int J Infect Dis. 2020;98:84-9. https://doi.org/10.1016/j.ijid.2020.06.038.

\section{Authors and Affiliations}

Eva Tabernero ${ }^{1,2}(1) \cdot$ Luis A. Ruiz $^{1,3} \cdot$ Pedro P. España $^{4} \cdot$ Raúl Méndez $^{5,6} \cdot$ Leyre Serrano $^{1,3} \cdot$ Borja Santos $^{7}$. Ane Uranga ${ }^{4} \cdot$ Paula González ${ }^{5,6} \cdot$ Patricia Garcia $^{4} \cdot$ Antoni Torres $^{8} \cdot$ Rosario Menendez $^{5,6} \cdot$ Rafael Zalacain $^{1}$

Luis A. Ruiz

luisalberto.ruiziturriaga@osakidetza.eus

Pedro P. España

pedropablo.espanayandiola@ osakidetza.eus

Raúl Méndez

rmendezalcoy@gmail.com

Leyre Serrano

leyre.serranofernandez@osakidetza.eus

Borja Santos

borja.santoszorrozua@osakidetza.eus

Ane Uranga

ane.urangaecheverria@osakidetza.eus

Paula González

paulagonzalezjimenez@gmail.com

Patricia Garcia

patricia.garciahontoria@ osakidetza.eus

Antoni Torres

atorres@clinic.cat

Rosario Menendez

rosmenend@gmail.com

Rafael Zalacain

rafael.zalacainjorge@osakidetza.eus
1 Pneumology Service, Hospital Universitario Cruces, 48903 Barakaldo, Bizkaia, Spain

2 Biocruces Bizkaia Health Research Institute, Barakaldo, Spain

3 Department of Immunology, Microbiology and Parasitology, Facultad de Medicina y Enfermería, Universidad del País Vasco/Euskal Herriko Unibertsitatea UPV/EHU, Leioa, Bizkaia, Spain

4 Pneumology Service, Hospital Universitario Galdakao-Usansolo, Galdakao, Bizkaia, Spain

5 Pneumology Service, Hospital Universitari I Politècnic La Fe, Valencia, Spain

6 Instituto de Investigación Sanitaria (IIS) La Fe, Valencia, Spain

7 Bioinformatics and Statistics Unit, Biocruces Bizkaia Health Research Institute, Barakaldo, Spain

8 Pneumology Service, Hospital Clinic/Institut D’Investigacions Biomediques August Pi I Sunyer (IDIBAPS), University of Barcelona, Barcelona, Spain 